\title{
Aging and auditory temporal sequencing: Ordering the elements of repeating tone patterns
}

\author{
LAUREL J. TRAINOR and SANDRA E. TREHUB \\ University of Toronto, Toronto, Ontario, Canada
}

\begin{abstract}
In a series of experiments, we examined age-related differences in adults' ability to order sequences of tones presented at various speeds and in contexts designed to promote or to impede stream segregation. In Experiment 1, 32 listeners (16 young, 16 old) were required to identify two repeating sequences that consisted of four tones (two from a high and two from a low frequency range) in different order. In Experiment 2, 32 listeners were required to judge whether the two recycled patterns from Experiment 1 were the same or different. In Experiment 3, four young and four old listeners were tested on the tasks of Experiment 2 over an extended period. In Experiment 4, 16 young and 16 old listeners were tested with sequences that were not recycled and were composed of tones drawn from a narrow frequency range. Elderly adults were less able than young adults to distinguish between tone sequences with contrasting order, regardless of the speed of presentation, the nature of the task (identification vs. same/different), the amount of practice, the frequency separation of the tones, or the presence or absence of recycling. These findings provide evidence of a temporal sequencing impairment in elderly listeners but reveal no indication of age differences in streaming processes.
\end{abstract}

There is little understanding of the speech comprehension deficits that occur in later life. Although age-related changes in auditory sensitivity are apparent (for a review, see Robinson \& Sutton, 1979), these changes in peripheral processing cannot account for the magnitude of the speech perception problems experienced by elderly listeners (Feldman \& Reger, 1967; Hayes, 1981; Olsho, Harkins, \& Lenhardt, 1985; Working Group on Speech Understanding and Aging, 1988). Central deficits seem to be implicated (Hawkins \& Presson, 1986), but progress in the specification of relevant mechanisms or processes has been limited.

Temporal sequencing ability, which is critical to the speech perception process, has been linked to developmental language delays and learning disabilities (Tallal \& Stark, 1985a, 1985b). Proficiency in temporal sequencing tasks seems to depend on many factors, including the number of elements in the test sequences, the occurrence of single or repeating sequences (e.g., Warren, 1972), and practice (Divenyi \& Hirsh, 1974), as well as on whether the stimuli are speech sounds (Warren, Obusek, Farmer, \& Warren, 1969). The response measure is also relevant, with judgments of order yielding poorer performance than same/different judgments (Warren \& Byrnes, 1975), and verbal responses yielding poorer performance than nonverbal responses (Warren \& Obusek, 1972). In the present investigation, we examined the possibility of temporal sequencing deficits in later life.

This research was funded by grants from the Natural Sciences and Engineering Research Council of Canada and The University of Toronto to S. E. Trehub. Reprint requests should be sent to $\mathrm{L}$. J. Trainor or S. E. Trehub, Centre for Research in Human Development, University of Toronto, Erindale Campus, Mississauga, Ontario, Canada L5L 1 C6.
Grouping mechanisms are also critical to the perception of sound sequences such as speech. The auditory stimuli that reach our ears do not contain separate information from different sound sources, but rather a combination of information from all sources, creating the need for parsing or grouping mechanisms to separate the incoming information into appropriate streams or auditory objects (Bregman, 1981). Bregman (1981) has proposed heuristic rules for parsing complex auditory input, with the ideal stream (i.e., information emanating from one source) maintaining frequency and spatial continuity, and its component sounds being relatively similar in timbre, loudness, and other characteristics. The perceptual separation of repeating tone sequences into two or more streams has been found to depend on the frequency separation of the tones as well as on the rate of presentation (see Miller \& Heise, 1950; van Noorden, 1975). The larger the frequency separation and the faster the rate of presentation, the greater the probability of hearing separate streams. One consequence of primary auditory stream segregation is that listeners have considerable difficulty perceiving the order of temporally contiguous elements from different streams but not those within a stream (Bregman \& Campbell, 1971). Thus, the phenomenon of auditory stream segregation offers opportunities for studying perceptual organization in general and temporal sequencing in particular. The implications of aging for temporal sequencing or auditory stream segregation are unknown, because neither process has been investigated with older adults.

There are indications that temporal factors may be of particular importance for aging listeners. For example, conditions involving reverberated, overlapping, or interrupted speech lead to considerably greater age-related 
deficits than do conditions of competing messages or those involving frequency distortion (Bergman et al., 1976). Time-compressed speech also poses difficulties for older listeners (Bergman, 1971; Bergman et al., 1976; Konkle, Beasley, \& Bess, 1977; Sticht \& Gray, 1969), although this may be related to high-frequency hearing loss (see Working Group, 1988, p. 878). Some researchers (e.g., Wingfield, Poon, Lombardi, \& Lowe, 1985) attribute this difficulty to reduced processing speed (i.e., central dysfunction) in the elderly rather than to degradation of the signal (i.e., peripheral dysfunction). Consistent with this interpretation is their finding of greater discrepancies between young and elderly adults for meaningless than for meaningful speech sequences (Wingfield et al., 1985).

There is much to be gained from the study of auditory pattern perception with relatively unfamiliar materials, particularly when age-related differences are at issue. Familiar materials such as speech or well-structured tunes may engage highly practiced routines and make it difficult to separate basic perceptual problems of segmentation and sequencing from those of accessing stored representations. One can minimize the use of overlearned strategies with patterns that are not readily amenable to efficient encoding. These considerations guided the construction of sequences for the present investigation.

In the following series of experiments, we examined age-related changes in adults' ability to order sequences of notes presented at varying speeds and in varying streaming contexts. Two test sequences were designed so as to sound identical under conditions of stream segregation (e.g., rapid speeds) and distinguishable by the order of their component tones under conditions promoting their perception in one stream (e.g., slow speeds; see Figure 1). Older listeners, by virtue of slower cognitive processing (e.g., see Salthouse, 1985), could be expected to have greater difficulty than younger listeners in maintaining the temporal coherence of sequences (i.e., perceiving them in one stream) at fast speeds. Thus, an age-related deficit that was primarily organizational would lead to similar performance by older and younger adults at slower speeds but to divergent performance at faster speeds. On the other hand, a primary temporal sequencing deficit would lead to poorer temporal-order perception for the elderly, regardless of the speed of presentation. Deficits in both organization (streaming) and temporal sequencing would generate age-related differences at all speeds (except when young and old performed at chance levels) but more pronounced differences at faster speeds.

\section{EXPERIMENT 1}

\section{Method}

Subjects. There were 16 young participants (undergraduate students $18-25$ years; $M=21$ years) and 16 elderly participants

A

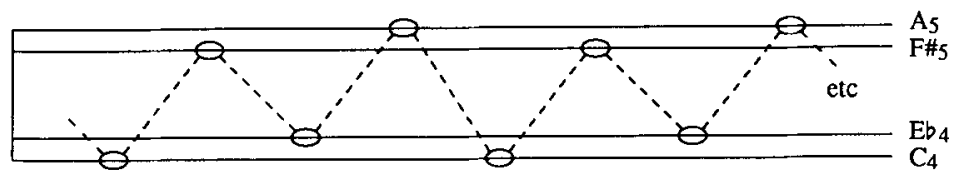

B
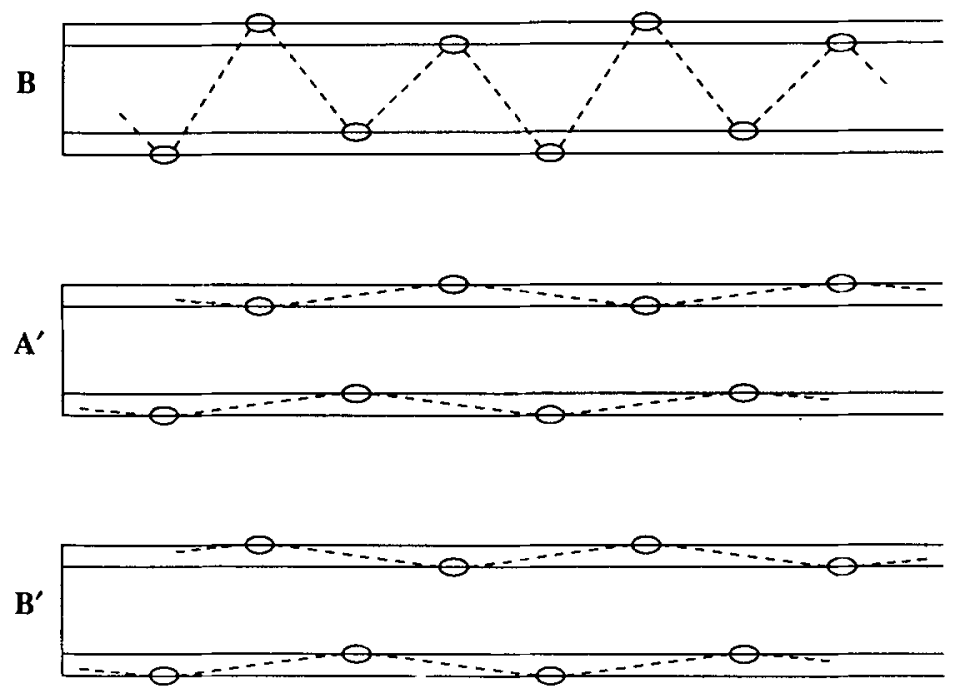

Figure 1. The stimuli for Experiment 1, from top to bottom: Pattern A organized in one stream, Pattern B organized in one stream, Pattern A organized in two streams, Pattern B organized in two streams. The subscript for each note name refers to the octave from which the note is drawn. $C_{4}$ is middle $C$; therefore, $E_{4}^{b}$ is from the same octave, and $F_{s}^{*}$ and $A_{s}$ are from the next higher octave. 
(active, healthy senior citizens $63-77$ years; $M=69$ years). One additional young subject and 2 older subjects were excluded for failure to achieve the training criterion (see Procedure).

Apparatus and Stimuli. Testing took place in a double-walled sound-attenuating chamber. Patterns of sine-wave tones were generated digitally and played by an Amiga 1000 computer through an Amiga 1080 monitor at an average intensity of 65-68 dB SPL (measured at the location of the listener's head), according to each listener's preference. There were two patterns of four tones each, with each tone $85 \mathrm{msec}$ in duration (including rise and decay times of $9 \mathrm{msec}$ ). Both patterns consisted of the same four tones in different order. Two of the tones were relatively high in pitch $\left(F_{s}^{\text {: }}: 740 \mathrm{~Hz}\right.$, and $\left.A_{5}: 880 \mathrm{~Hz}\right)$, the other two were low $\left(C_{4}: 262 \mathrm{~Hz}\right.$ and $E_{4}^{b}$ : $330 \mathrm{~Hz}$ ); both patterns alternated high and low notes such that separate stream formation by frequency similarity was likely at faster speeds (see Figure 1). The sequences were perceptually distinct only if each was heard in one stream. If the four tones were placed within one octave, they would form a diminished chord, which is considered tonally ambiguous (i.e., without a note as tonal center). Each pattern was recycled (repeated continuously) for approximately $10 \mathrm{sec}$. At onset and offset, the patterns faded in and out to preclude the identification of initial and final intervals. The maximum intensity of a pattern was reached by the third presentation. During test trials, the patterns were presented at eight different speeds, with onset-to-onset time of successive tones being $100,160,220,280$, $340,400,460$, and $520 \mathrm{msec}$. Because tone duration was constant, a slower onset-to-onset time implied longer silent periods between tones.

Procedure. To confirm that participants were functioning at a normal intellectual level, they were given a short form of the Mill Hill vocabulary synonyms test, which took about $5 \mathrm{~min}$ to administer. To rule out the possibility of a hearing impairment that could interfere with the experimental tasks, all participants were given an individual audiometric evaluation to establish thresholds for pure tones at $250,500,1000,2000,3000,4000$, and $8000 \mathrm{~Hz}$. Following these preliminary tasks, the participants listened to fournote demonstrations of each pattern with onset-to-onset times of $1,000 \mathrm{msec}$, and each tone $900 \mathrm{msec}$ in duration. Visual depictions of the demonstration (similar to those in Figure 1, top two panels) were presented simultaneously on the monitor. The listeners were instructed to repeat the demonstrations until they could readily distinguish the two patterns. Subsequently, the listeners were not provided with concurrent visual displays, but they had a diagram similar to Figure 1 (top two panels) for reference. There were two training phases. In the first, the onset-to-onset time between successive tones was $1,000 \mathrm{msec}$, the tones were $200 \mathrm{msec}$ in duration, and each sequence was presented for approximately $10 \mathrm{sec}$. On each trial, the listeners indicated which pattern was presented by pressing Button A or B (two-alternative, forced-choice) on a twobutton box. The computer screen indicated "correct" or "incorrect," and the next trial followed automatically after $1 \mathrm{sec}$. The order of trials with Pattern A or B was random, with the constraint that no more than three trials of one type could occur in succession. The listeners were required to meet a training criterion of five consecutive correct responses within 60 trials. Those who achieved this training criterion proceeded to the second phase of training, which differed only as follows. The tones were $150 \mathrm{msec}$ in duration, and one of three onset-to-onset speeds $(600,750,900 \mathrm{msec})$ was chosen randomly for each trial, subject to the additional constraint that, of the six different types of trials ( 2 patterns $\times 3$ speeds), no two in a row could be the same. Again, the listeners were required to achieve five successive correct responses within 60 trials. The listeners who completed the second training phase proceeded immediately to the test phase, which consisted of 64 trials in four blocks of 16 trials each, with each block consisting of a random order of the two patterns $(\mathrm{A}, \mathrm{B})$ presented at 8 speeds $(100-520 \mathrm{msec})$. As in training, feedback was provided after each trial. Following each block of 16 trials, the listeners were given the option (by a message on the monitor) of returning to the original demonstration patterns before proceeding to the next block of trials. The time required to complete the preliminary tasks, demonstration, training, and test procedures varied considerably from listener to listener, with a maximum of $1 \frac{1 / 2}{h}$.

\section{Results}

The older listeners performed significantly better than the younger on the vocabulary test $[t(30)=5.82$, $p<.001]$, ruling out subnormal intellectual functioning for the former group. The pure tone average (PTA) calculated from thresholds for the better ear at 500,1000, and $2000 \mathrm{~Hz}$ deviated by less than $25 \mathrm{~dB}$ from the standard for normal, young adults (American National Standards Institute, 1970) for all participants. Note that all the tone sequences were well under $2000 \mathrm{~Hz}$. Moreover, there were no significant correlations between PTA and performance (overall percent correct) for older $(r=0.148$, $p<.58)$ or for younger $(r=-0.321, p<.22)$ listeners. Similarly, there were no significant correlations between vocabulary scores and overall percent correct $(r=0.21, p<.42$ for younger listeners; $r=0.26$, $p<.34$ for older listeners). The pattern of findings for vocabulary scores, PTA, and the relation between these and performance was similar for all the experiments in this report.

The performance on the temporal order tasks was surprisingly poor. At the slowest speed, the younger listeners only achieved an average of $77 \%$ correct, and the older subjects $67 \%$ correct. A mixed-design analysis of variance was performed with age (young, old) as a betweensubjects variable, and speed of presentation and sequence type (A, B) as within-subjects variables. The dependent variable was $d^{\prime}$, a transformation of the percent correct scores based on the forced-choice tables of signal detection theory (Swets, 1964, pp. 682-683). Scores of $100 \%$ and $0 \%$ were not considered to reflect underlying sensitivity but rather to reflect sampling error (Macmillan \& Kaplan, 1985); thus, all were adjusted so as to be $1 / 2$ closer to the mean, 2 in this case (i.e., scores of $0,1,2,3$, and 4 were transformed to $1 / 2,1 \frac{1}{2}, 2,2 \frac{1}{2}$, and $3 \frac{1}{2}$ ) before the $d^{\prime}$ transformation was performed. ${ }^{1}$ There were significant main effects of age $[F(1,30)=5.02, p<.05]$, and speed $[F(7,210)=30.75, p<.001]$, but there were no significant interactions (see Figure 2).

We examined possible effects of practice on the young and elderly listeners, with age, speed of presentation, and trial block $(1,2,3,4)$ as independent variables, and percent correct (transformed to $d^{\prime}$, as above) as the dependent variable. In addition to the main effects of age and speed, there was a significant interaction between age and block $[F(3,90)=3.39, p<.05]$, but no significant block effect. The younger listeners continued to improve on later trials; the older listeners showed some improvement in the second trial block, but performance decrements became evident in subsequent trial blocks, indicating pos- 


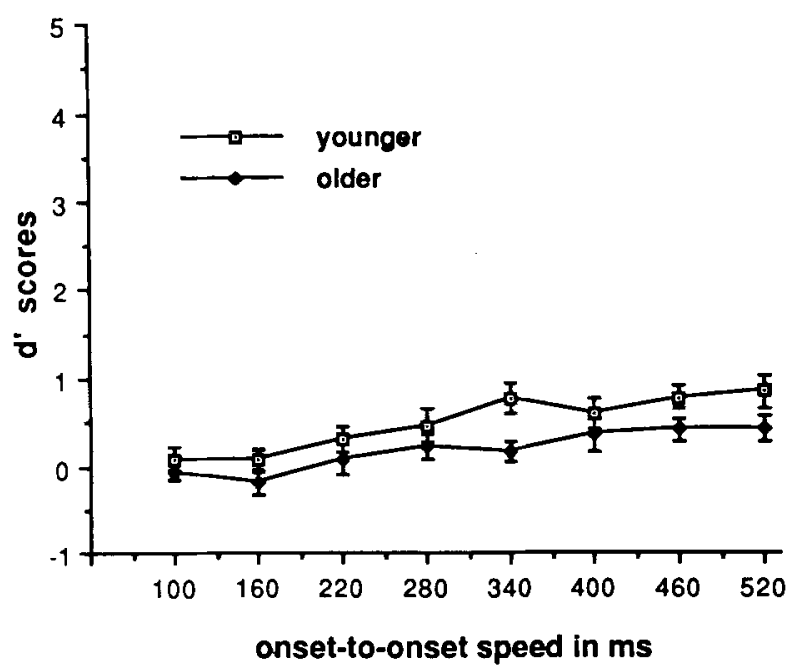

Figure 2. Experiment 1: $d^{\prime}$ scores for younger and older listeners as a function of speed. Error bars indicate the standard error of the mean.

sible fatigue. Moreover, there were large individual differences for both groups of listeners, and the best elderly listeners performed better than the worst younger listeners.

\section{Discussion}

The principal finding was that the older listeners performed more poorly than did the younger listeners, even at the slowest speeds. The simplest explanation is that older listeners as a group are impaired in the ability to order recycling auditory sequences. Age-related differences in the speed at which the sequences split into two streams would have generated an interaction between age and speed but this was not found. However, the interaction between age and blocks, reflecting poorer performance by the older listeners on later than on earlier trials, may have obscured a potential age $X$ speed interaction. The requirement of identifying each sequence as $A$ or $B$ seemed to create some strain on the subjects, particularly the elderly. Accordingly, we attempted to replicate the experiment with an alternative task. In Experiment 2, we used similar stimuli but eliminated absolute judgments in favor of same/different judgments.

\section{EXPERIMENT 2}

\section{Method}

Subjects. There were 16 young $(M=21$ years) and 16 elderly ( $M=69$ years) participants.

Apparatus and Stimuli. These were identical to those in Experiment 1 apart from the following differences: Patterns of sinewave tones were played through a Canton loudspeaker with an average intensity of $73 \mathrm{~dB}$ SPL. Instead of fading the patterns in and out, the initial note was randomized, and the initial and final notes of each sequence were identical. Each note was $75 \mathrm{msec}$ in duration, including rise and decay times of $9 \mathrm{msec}$. The patterns were recycled for about $7 \mathrm{sec}$ and onset-to-onset speeds were 80, 140, $200,260,320,380,440$, and $500 \mathrm{msec}$.

Procedure. The procedure was identical to that of Experiment 1 apart from the following differences. The demonstrations consisted of two cycles or repetitions of Patterns A and B, and there was no training phase. On each trial, the listeners heard two successive recycling patterns (always starting on the same note) separated by $1 \mathrm{sec}$, and they were required to make a same/different judgment as to the order of the notes by pressing one of two buttons. They also rated their confidence in each judgment on a scale from 1 (guessing) to 7 (highly confident). After each judgment, feedback appeared on the screen and the next trial was presented automatically after $1 \mathrm{sec}$. There were two parts to the experiment. In the first part, the two patterns to be compared were presented at the same speed; in the second, the first pattern was always at the slowest speed ( $500 \mathrm{msec}$ onset-to-onset) and the second varied in speed. Half of the subjects received same-speed trials first; the other half received different-speed trials first. Each part of the experiment consisted of 4 practice trials and 64 test trials, in two blocks of 32 trials each. $A$ random order of the 8 test speeds $\times 4$ combinations of patterns (same: A-A, B-B; different: A-B, B-A) was calculated for each group of 32 trials.

\section{Results}

Again, the performance was relatively poor, with the younger listeners reaching a maximum of $77 \%$ correct at the slowest speed, and the older listeners $65 \%$ correct. Ratings of confidence were correlated with accuracy for the younger listeners $(r=0.22, p<.0001$ and $r=0.16, p<.0001$ for the first and second parts of the experiment, respectively) but not for the older listeners ( $r=0.0039$ and $r=0.012$, respectively). No further analysis involving confidence ratings was performed. A mixed-design analysis of variance was performed with age as a between-subjects variable and speed of presentation and experiment type (same-speed, different-speed comparisons) as within-subjects variables. The dependent variable was $d^{\prime}$, a transformation of the percent correct scores for same responses, given same stimuli, and same responses, given different stimuli, according to the same/different tables of signal detection theory (Kaplan, Macmillan, \& Creelman, 1978). The $d^{\prime}$ scores for both groups are shown in Figure 3. Percent correct scores were transformed prior to the $d^{\prime}$ transformation, as in Experi-

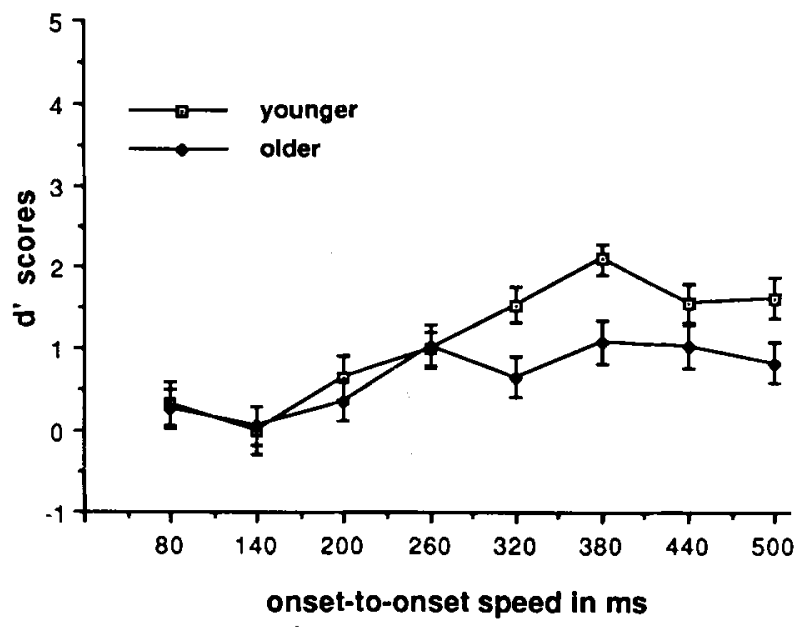

Figure 3. Experiment 2: $d^{\prime}$ scores for younger and older listeners as a function of speed. Error bars indicate the standard error of the mean. 
ment 1. There were significant main effects of age $[F(1,30)=6.11, p<.05]$ and speed $[F(7,210)=10.89$, $p<.001]$, but there was no significant interaction between age and speed. The main effect of experiment type and all interactions involving experiment type were not significant.

A second analysis of variance was performed to examine the effect of blocks: age was a between-subjects variable; speed of presentation and blocks $(1,2)$ were withinsubjects variables. The dependent variable $d^{\prime}$ was obtained as above. Main effects of age and speed were significant. There was no effect of blocks, nor were there any significant interactions with blocks. Again, large variations in performance characterized both age groups, and the scores of the best older and worst younger listeners overlapped.

\section{Discussion}

The pattern of performance was similar to that of Experiment 1 , except that the troublesome age $\times$ trial-blocks interaction was no longer present. (Performance in terms of percent correct was similar in Experiments 1 and 2, but the same/different task is considered more difficult than the two-alternative, forced-choice identification task in signal detection theory; thus $d^{\prime}$ scores are higher in Experiment 2.) The older listeners simply performed more poorly than the younger, regardless of speed, and there was no indication that performance would improve at speeds slower than $500 \mathrm{msec}$. These findings, together with those in Experiment 1, point to age-related problems in temporal order discrimination. The finding that elderly listeners performed no more poorly on comparisons across speeds than on those of equal speed (experiment-type manipulation) indicates that, to the extent that elderly listeners can encode the temporal order of tones, their representation is independent of speed. The older listeners had difficulty with the confidence rating task, some of them choosing the same rating on every trial and providing verbal corroboration of feelings of equivalent confidence.

In psychoacoustic research, it is common to obtain many judgments for each stimulus value from highly trained listeners (e.g., see Divenyi \& Hirsh, 1974). It was possible, then, that lack of practice could have been responsible for the relatively low level of performance and that this might have affected the older listeners more adversely than the younger listeners. Thus, similar performance at slower speeds might be evident in highly practiced listeners of both age groups. Because many of the older participants in Experiments 1 and 2 found the task difficult and tiring, it was inappropriate to request their participation over several days. Instead, the four elderly listeners from Experiments 1 and 2 with the best overall performance were selected to participate for $1 \mathrm{~h}$ a day for 5 days. Four younger participants who had performed relatively well also participated in this extended version of Experiment 2 .

\section{EXPERIMENT 3}

\section{Method}

Four elderly $(65,65,69,73$ years $)$ and four younger $(20,21$, 24, 25 years) listeners from Experiments 1 and 2 were tested with Condition 1 of Experiment 2 (same-speed comparisons) followed by Condition 2 (different-speed comparisons) over five sessions (days).

\section{Results}

If we consider the first three sessions as practice, then we can consider the data from the last two sessions as reflecting the performance of practiced listeners. It can be seen in Figure 4 that, although the performance levels are higher than they were in the previous experiment, the pattern of results is similar. These data were submitted to an analysis of variance, with age as a between-subjects variable, and speed of presentation and experiment type as within-subjects variables. There were significant main effects of age $[F(1,6)=6.28, p<.05]$ and speed $[F(7,42)=17.02, p<.001]$, but there was neither an age $X$ speed interaction nor any effects involving experiment type.

To examine changes in performance across sessions, the data from all five sessions were submitted to an analysis of variance. The main effect of session was significant $[F(4,28)=5.67, p<.001]$, indicating improvement across sessions. The interaction of age $\times$ session failed to reach conventional levels of significance $[F(4,28)=$ $2.73, p<.06$ ]; with only 8 subjects, statistical power was obviously low. Figure 5 indicates, however, that the trend is toward greater improvement for the younger than for the older listeners after five sessions.

Figure 6 shows the performance of each participant averaged across all five sessions, as well as performance averaged across the last two sessions. It can be seen that

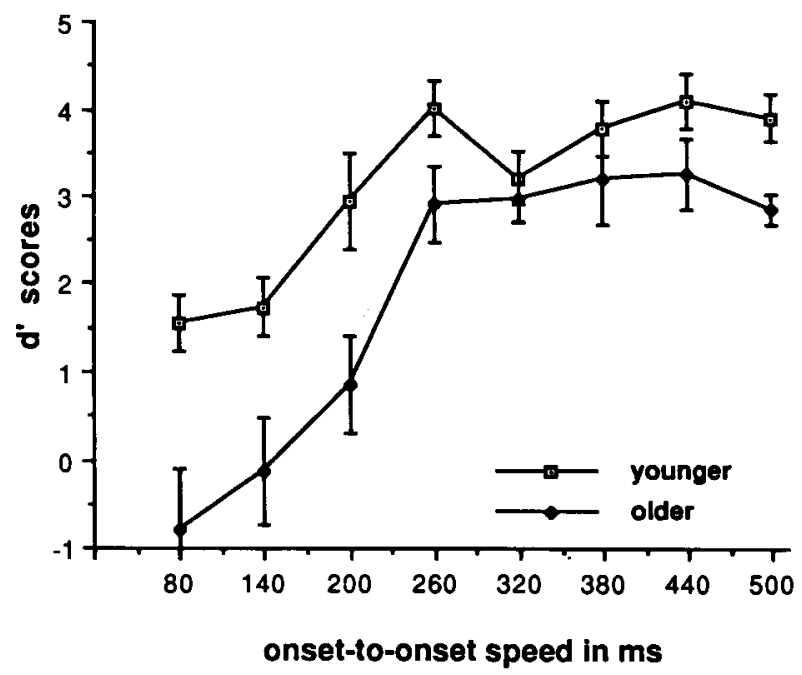

Figure 4. Experiment 3: $d^{\prime}$ scores for younger and older listeners as a function of speed. Scores are averaged over the last two sessions. Error bars indicate the standard error of the mean. 


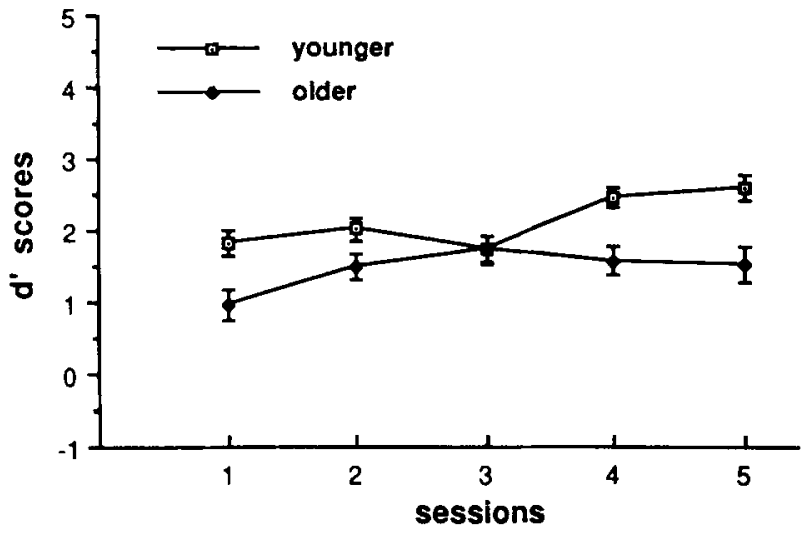

Figure 5. Experiment 3: $d^{\prime}$ scores for younger and older listeners as a function of session. Error bars indicate the standard error of the mean.

the shapes of the individual functions are similar to those of the group, with gradual improvement in performance as speed decreases.

\section{Discussion}

Although performance improved over the five sessions, the pattern of age effects with practiced listeners remained similar to the pattern observed in Experiments 1 and 2, with the older listeners performing more poorly than the younger listeners, regardless of speed. Furthermore, there was evidence against the view that the elderly improve more with practice than the young, making it unlikely that iack of practice was the factor responsible for age-related performance deficits in Experiments 1 and 2. It should also be noted that the elderly participants in Experiment 3 were a select group of the best performers from Experiments 1 and 2, so that the average elderly listener is likely to perform considerably less well.

The findings in Experiments 1, 2, and 3 indicate that elderly listeners have difficulty ordering sequential stimuli, even at relatively slow speeds when a sequence is presumably heard in one stream. Furthermore, the absence of age $\times$ speed interactions suggests that there is no difference between young and elderly listeners in stream organization per se. It is possible, however, that elderly adults are unable to maintain the temporal coherence of sequences such as those in Experiments 1 and 2 at any speed. Factors other than speed can promote stream formation, including recycling or repetition of patterns and component tones with dissimilar pitch (Bregman, 1981). In Experiment 4, we attempted to promote coherence or reduce the potential for separate stream formation by eliminating the recycling of patterns and narrowing the frequency range.

\section{EXPERIMENT 4}

\section{Method}

Subjects. There were 16 younger $(M=22$ years) and 16 older $(M=70$ years) participants.
Apparatus and Stimuli. These were identical to Experiment 2 apart from the following differences. There was no recycling of the four-tone patterns. To preclude identification by obvious cues such as the initial or final note, a fifth note was added to each pattern to make the initial and final notes identical, and the starting note was varied randomly between trials. The two high notes from Patterns A and B were transposed an octave downward so that the notes were equally spaced, forming a diminished chord, with the interval from the lowest note to the highest note being $3 / 4$ of an octave. The note frequencies were $\mathrm{C}_{4}, 262 \mathrm{~Hz} ; \mathbf{E}_{4}^{\mathrm{b}}, 330 \mathrm{~Hz} ; \mathrm{F}_{4}^{*}$, $370 \mathrm{~Hz}$; and $\mathrm{A}_{4}, 440 \mathrm{~Hz}$.

Procedure. The procedure was identical to that of Experiment 1 apart from the following differences. There were 128 test trials, in two blocks of 64 . Each block had two groups of 32 trials, with a random ordering of the 8 speeds $(80,140,200,260,320,380$, $440,500 \mathrm{msec}$ onset-to-onset) $\times$ four trial types (same: A-A, BB; different: A-B, B-A), with the constraint that each group of 32 trials had 8 trials with each of the four different starting notes.

\section{Results}

A mixed-design analysis of variance was performed with age as a between-subjects variable, and speed of presentation and trial blocks $(1,2)$ as within-subject variables. The dependent variable was $d^{\prime}$, obtained from percent correct scores, as in Experiment 2. There were significant main effects of age $[F(1,30)=6.77, p<.05]$, and speed $[F(7,210)=3.57, p<.001]$, but no significant interactions (see Figure 7).

\section{Discussion}

The older listeners exhibited deficits in temporal order discrimination even when the test sequences had a narrow frequency range and were not recycled. In other words, the older listeners performed more poorly than the younger listeners under conditions that were unlikely to promote separate stream formation. As in Experiments 1 and 2, the older listeners were not differentially penalized by the faster speeds. These findings provide further evidence of a general temporal sequencing deficit with aging that cannot be explained by organizational deficits. Surprisingly, the younger listeners failed to achieve average performance levels exceeding $75 \%$ correct at any speed. Thus, discerning the temporal order of four-tone sequences appears to be difficult, even for young listeners under relatively favorable circumstances.

\section{GENERAL DISCUSSION}

The principal finding was that the elderly adults were less able than the younger adults to distinguish between note sequences with contrasting order, regardless of the streaming organization promoted by changes in speed of presentation and frequency separation. This performance deficit on the part of the elderly listeners was unaffected by the nature of the task (identification vs. same/different) or the amount of practice. We had anticipated that slower processing in the elderly might lead to "premature"' stream segregation and, consequently, to greater performance decrements at faster speeds, but this was not the case. Instead, the failure to obtain interactions between 


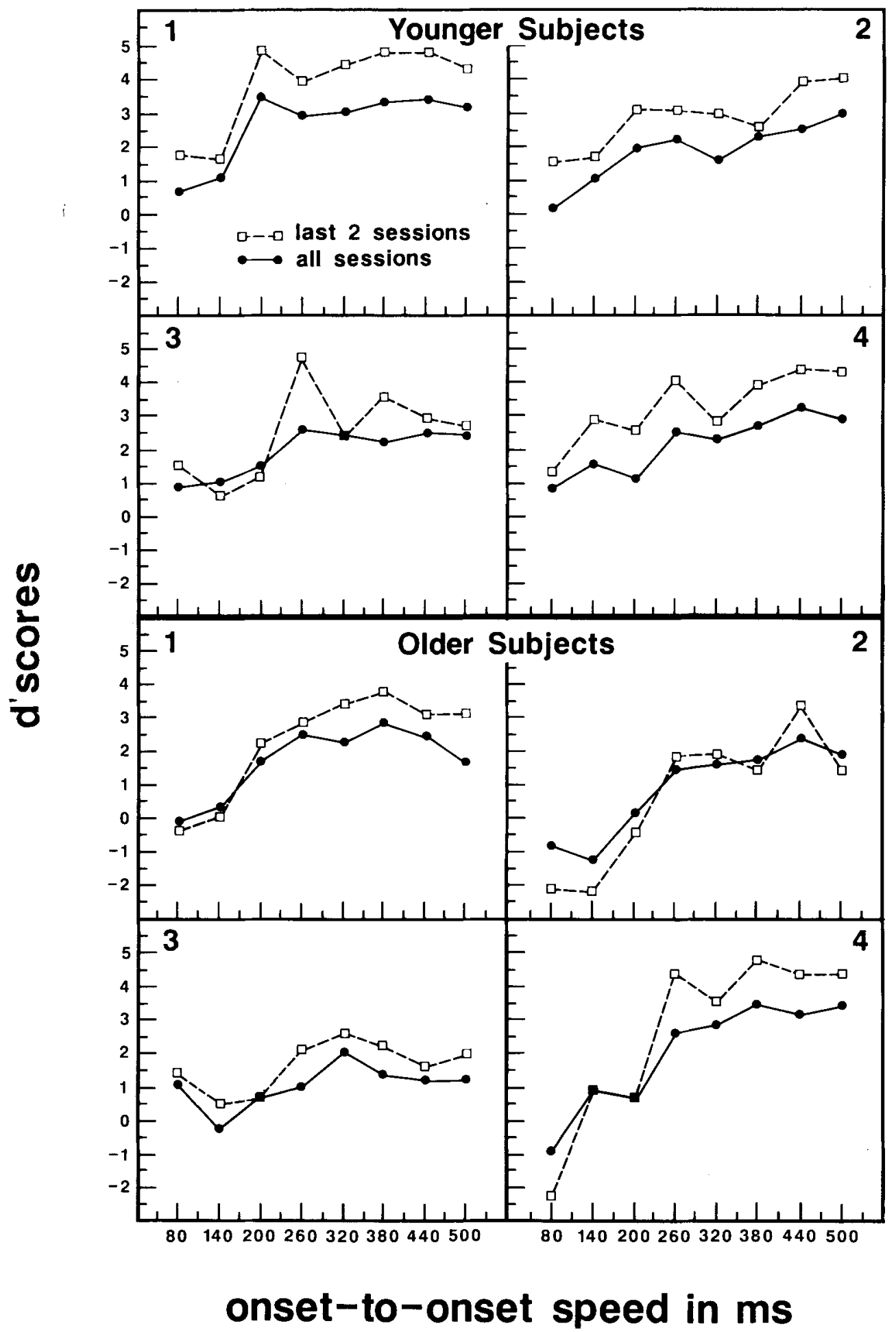

Figure 6. Experiment 3: $d^{\prime}$ scores for each listener as a function of speed.

age and speed of presentation suggests the presence of a specific age-related deficiency in temporal order discrimination that is independent of stream organization.

Are there other factors that might account for these performance differences between young and elderly adults?
Although there is some evidence that elderly listeners have decrements in temporal acuity (Ludlow, Cudahy, \& Bassich, 1982; Robin, Royer, \& Gruhn, 1985), these are unlikely to be relevant here because the shortest note duration in the present study $(75 \mathrm{msec})$ was well above the 


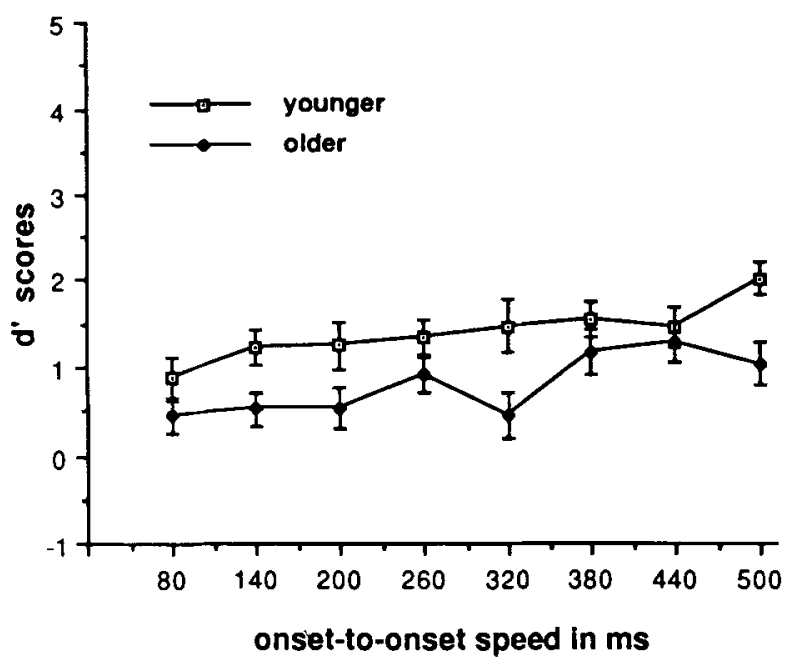

Figure 7. Experiment 4: $d^{\prime}$ scores for younger and older listeners as a function of speed. Error bars indicate the standard error of the mean.

threshold of detectability. The issue in this case is not the detection of notes but, rather, the accurate perception of their order.

Stimulus uncertainty may have contributed to the observed age differences. On each trial, listeners could not predict the speed of the sequences or the note on which they would begin. Perhaps uncertainty associated with this situation led to the relatively low levels of performance by all listeners (see Espinoza-Varas \& Watson, 1986) but affected the elderly more than the young. It seems unlikely, however, that problems associated with stimulus uncertainty could have accounted entirely for the age effect.

Craik (1986) has proposed deficiencies in self-initiated processing to account for the memory problems of the elderly. For example, the provision of explicit instructions for encoding leads to greater improvement in elderly than in young adults, indicating that the elderly fail to invoke appropriate strategies spontaneously (Rabinowitz, Ackerman, Craik, \& Hinchley, 1982). Nevertheless, the emergence of the same pattern of results across Experiments $1,2,3$, and 4 of the present report, regardless of differences in training and practice, makes it unlikely that instructional or strategic issues were principally responsible for the observed age differences in temporal order perception.

The performance on all tasks in the present investigation was relatively poor. Even at the slowest speeds, the younger listeners achieved average performance levels of $77 \%$ correct (in Experiments 1 and 2), and there was no indication of potential improvement at even slower speeds. A few factors may have contributed to the low level of performance. Recall that note duration remained constant at all speeds, so that interstimulus intervals were longer at slower speeds. Although silent intervals between the notes of a sequence can aid temporal discrimination (see
Nickerson \& Freeman, 1974), this benefit may reach a maximum at a particular interval duration, with longer intervals reducing the coherence of sequences. Moreover, the nontonal structure of the sequences may have depressed performance. The notes of the sequences formed diminished chords, which are tonally ambiguous. This was a deliberate strategy to control for differences, possibly age-related, in exposure to music, but it may have generated particular encoding difficulties (see Cuddy, Cohen, \& Mewhort, 1981; Watkins \& Dyson, 1985).

For both the younger and the older listeners, auditory sensitivity (i.e., pure tone average) was uncorrelated with performance on the temporal order tasks, suggesting that central auditory mechanisms may be implicated, as is thought to be the case for speech comprehension difficulties in the elderly (Marshall, 1981; Working Group, 1988). The large individual differences obtained for both age groups are in accord with previous evidence of individual differences on temporal sequencing tasks (Johnson, Watson, \& Jensen, 1987). Other auditory temporal abilities, such as temporal acuity, have revealed considerably smaller individual differences (Johnson et al., 1987) as well as stronger relations to peripheral auditory functioning (see Scharf \& Buus, 1986, for a review).

The observed deficits in temporal sequencing may be related to the speech comprehension difficulties that are experienced by many elderly persons. Note, however, that the best elderly listeners in the present study performed better than the worst younger listeners, who would be unlikely to have speech reception problems. Indeed, little is known about individual differences in speech perception among the elderly. However, if these highly performing elderly were also free of speech comprehension difficulties, this would provide evidence for the proposed correlation between temporal sequencing and speech comprehension. It would also be of considerable interest to ascertain whether age-related temporal sequencing deficits are evident in the visual domain or whether these deficits are modality specific.

Dysphasic children, who are also impaired on temporal sequencing tasks, profit more from decreased speeds of presentation than do normal children (see Tallal, 1980, 1981). The present elderly listeners, on the other hand, did not benefit more than younger listeners from slower speeds, suggesting that a general slowing of information processing (see Salthouse, 1985) was not principally responsible for their poor performance.

From the perspective of the present research, the relation between order judgments and streaming remains unclear (see also Barsz, 1988). Streaming is often measured indirectly by the ability to discriminate temporal order, the assumption being that it is possible to discern the order of elements within a stream but not between streams (Bregman, 1978, 1981). However, there was no sharp boundary in the listeners' abilities to discriminate the order of sounds as the speed of presentation increased, even after 5 days of practice. Rather, the listeners improved gradu- 
ally as the speed decreased. This pattern of performance was similar for the recycled sequences of Experiments 1, 2 , and 3, as well as for the nonrecycled, same-octave sequences of Experiment 4, where one would not expect stream segregation. This implies either that the perception of one or more streams is not categorical, or that there is an extensive range of speeds over which the probability of hearing one stream or two is similar. It is likely that organizing a group of notes into a single stream enhances, but does not guarantee, the preservation of information about temporal order.

In summary, we found evidence of an age-related deficit in temporal sequencing that was unrelated to listeners' auditory sensitivity or to the speed of presentation of tone sequences. Determining the relation between such temporal sequencing deficits and the speech perception difficulties of elderly listeners remains an important task for future research.

\section{REFERENCES}

American National Standards Institute (1970). American National Standard Specifications for Audiometers (ANSI S3.6-1969). New York: American National Standards Institute.

BARSz, K. (1988). Auditory pattern perception: The effect of tonal frequency range on the perception of temporal order. Perception \& Psychophysics, 43, 293-303.

Bergman, M. (1971). Hearing and aging. Audiology, 10, 164-171.

Bergman, M., Blumfield, V., Cascardo, D., Dash, B., LevitT, H., \& MARGULIES, M. (1976). Age-related decrement in hearing for speech: Sampling and longitudinal studies. Joumal of Gerontology, 31, 533-538.

Bregman, A. S. (1978). The formation of auditory streams. In J. Requin (Ed.), Attention and performance VII (pp. 63-75). Hillsdale, NJ: Erlbaum.

Bregman, A. S. (1981). Asking the "What For" question in auditory perception. In M. Kubovy \& J. R. Pomerantz (Eds.), Perceptual organization (pp. 99-118). Hillsdale, NJ: Erlbaum.

Bregman, A. S., \& CAMPBELL, J. (1971). Primary auditory stream segregation and segregation of order in rapid sequences of tones. Journal of Experimental Psychology, 89, 244-249.

CraIK, F. I. M. (1986). A functional account of age differences in memory. In F. Klix \& A. Hagendorf (Eds.), Human memory \& cognitive capabilities (pp. 409-422). Amsterdam: Elsevier.

Cuddy, L. L., Cohen, A. J., \& MewhorT, D. J. K. (1981). Perception of structure in short melodic sequences. Journal of Experimental Psychology: Human Perception \& Performance, 7, 869-883.

DIVENYI, P. L., \& HIRSH, I. J. (1974). Identification of temporal order in three-tone sequences. Journal of the Acoustical Society of America, 56, 144-151.

Espinoza-Varas, B., \& Watson, C. B. (1986). Temporal discrimination for single components of non-speech auditory patterns. Journal of the Acoustical Society of America, 80, 1685-1694.

Feldman, R. M., \& Reger, S. N. (1967). Relations among hearing, reaction time, and aging. Journal of Speech \& Hearing Research, 10, 479-495.

Hawkins, H., \& Presson, J. (1986). Auditory information processing. In K. R. Boff, L. Kaufman, \& J. P. Thomas (Eds.), Handbook of perception and human performance: Vol.II. Cognitive processes and performance (chap. 26). New York: Wiley-Interscience.

HAYES, D. (1981). Central auditory problems and the aging process. In D. S. Beasley \& G. A. Davis (Eds.), Aging: Communication processes and disorders (pp. 257-266). New York: Grune \& Stratton.

Johnson, D. M., WATSON, C. S., \& JENSEN, J. K. (1987). Individual differences in auditory capabilities. I. Journal of the Acoustical Society of America, 81, 427-438.
Kaplan, H. L., Macmillan, N. A., \& Creelman, C. D. (1978). Tables of $d^{\prime}$ for variable-standard discrimination paradigms. Behavior Research Methods \& Instrumentation, 10, 796-813.

Konkle, D. F., Beasley, D. S., \& Bess, F. H. (1977). Intelligibility of time-altered speech in relation to chronological aging. Journal of Speech \& Hearing Research, 20, 108-115.

Ludlow, C. L., Cudahy, E. A., \& Bassich, C. J. (1982). Developmental, age, and sex effects on gap detection and temporal order. Journal of the Acoustical Society of America, 71, S47.

Macmillan, N. A., \& KaPlan, H. L. (1985). Detection theory analysis of group data: Estimating sensitivity from average hit and falsealarm rates. Psychological Bulletin, 98, 185-199.

MARSHALL, L. (1981). Auditory processing in aging listeners. Journal of Speech \& Hearing Disorders, 46, 226-240.

Miller, G. A., \& Heise, A. (1950). The trill threshold. Journal of the Acoustical Society of America, 22, 637-638

Nickerson, R. S., \& Freeman, B. (1974). Discrimination of the order of the components of repeating tone sequences: Effects of frequency separation and extensive practice. Perception \& Psychophysics, 16, 471-477.

Olsho, L. W., Harkins, S. W., \& Lenhardt, M. L. (1985). Aging and the auditory system. In J. E. Birren \& K. W. Schaie (Eds.), Handbook of the psychology of aging (pp. 332-377). New York: Van Nostrand Reinhold.

Rabinowitz, J. C., Ackerman, B. P., Craik, F. I. M., \& HinchLEY, J. L. (1982). Aging and metamemory: The roles of relatedness and imagery. Joumal of Gerontology, 37, 688-695.

Robin, D. A., Royer, F. L., \& Gruhn, J. J. (1985, April). Age related changes in auditory temporal processing. Paper presented at the meeting of the Acoustical Society of America, Austin, Texas.

Robinson, D. W., \&utton, G. J. (1979). Age effect in hearing-A comparative analysis of published threshold data. Audiology, 18, 320-324.

SAlthouSE, T. A. (1985). Speed of behavior and its implications for cognition. In J. E. Birren \& K. W. Schaie (Eds.), Handbook of the psychology of aging (pp. 400-426). New York: Van Nostrand Reinhold.

Scharf, B., \& BuUs, S. (1986). Audition I: Stimulus, physiology, thresholds. In K. R. Boff, L. Kaufman, \& J. P. Thomas (Eds.), Handbook of human perception and performance: Vol. I. Sensory processes and perception (chap. 14). New York: Wiley-Interscience.

STicht, T., \& Gray, B. (1969). The intelligibility of time-compressed words as a function of age and hearing loss. Joumal of Speech \& Hearing Research, 12, 443-448.

SWETS, J. A. (1964). Signal detection and recognition by human observers. New York: Wiley.

TAllal, P. (1980). Perceptual requisites for language. In R. L. Schiefelbusch (Ed.), Nonspeech language and communication: Analysis and intervention (pp. 449-467). Baltimore: University Park Press.

TALlal, P. (1981). Language disabilities in children: Perceptual correlates. International Journal of Otorhinolaryngology, 3, 1-13.

TALLAL, P., \& STARK, R. E. (1985a). Identification of language-impaired children on the basis of rapid perception and production skills. Brain \& Language, 25, 314-322.

Tallal, P., \& STARK, R. E. (1985b). The relationship between auditory temporal analysis and receptive language development: Evidence from studies of developmental language disorder. Neuropsychologia, 23, 527-534.

VAN NoORden, L. P. A. S. (1975). Temporal coherence in the perception of tone sequences. Unpublished doctoral dissertation, Technische Hogeschool Eindhoven, Eindhoven, The Netherlands.

W ARREN, R. M. (1972). Perception of temporal order: Special rules for the initial and terminal sounds of sequences. Journal of the Acoustical Society of America, 52, 167. (Abstract)

WARREN, R. M., \& BYRNES, D. L. (1975). Temporal discrimination of recycled tonal sequences: Pattern matching and naming of order by untrained listeners. Perception \& Psychophysics, 18, 273-280.

WARREN, R. M., \& OBuSEK, C. J. (1972). Identification of temporal order within auditory sequences. Perception \& Psychophysics, 12 , 86-90. 
Warren, R. M., Obusek, C. J., Farmer, R. M., \& WArren, R. P. (1969). Auditory sequence: Confusion of patterns other than speech sounds or music. Science, 164, 586-587.

Watkins, A. W., \& Dyson, M. C. (1985). On the perceptual organization of tone sequences and melodies. In P. Howell, I. Cross, \& R. West (Eds.), Musical structure and cognition (pp. 71-119). London: Academic Press.

Wingfield, A., Poon, L. W., Lombardi, L., \& Lowe, D. (1985). Speed of processing in normal aging: Effects of speech rate, linguistic structure, and processing time. Journal of Gerontology, $\mathbf{4 0}$, 579-585.

Working Group on SPeEch Understanding and Aging. (1988). Speech understanding and aging. Journal of the Acoustical Society of America, 83, 859-895.
NOTE

1. Over the long run, no subject would be expected to achieve $100 \%$ or $0 \%$ correct in any condition of the current experiment. In fact, the $d^{\prime}$ transformation would not be appropriate in either case because $100 \%$ and $0 \%$ correct correspond to infinitely large $d^{\prime}$ scores in the positive and negative directions, respectively. However, in experiments with a limited number of trials, there is a sampling error that increases in magnitude as the number of trials decreases. With specialized populations (such as the elderly), large numbers of trials may be precluded. In such cases, occasional scores of $100 \%$ or $0 \%$ correct are assumed to result from sampling error, necessitating a transformation before conversion to $d^{\prime}$. The transformation used here is fairly conservative: the percent correct scores are compressed, making it more difficult to achieve significant effects.

(Manuscript received February 1, 1988;

revision accepted for publication October 20,1988 .) 